\title{
Methicillin Susceptible Panton -Valentine Leukocidin Positive $S$. Aureus Pneumonia in a Child with Novel Influenza H1N1 Infection
}

\author{
Liene Cupane*/***, Nina Pugacova*, Girts Aleksejevs*, Dace Berzina**/***, Dace Gardovska*/***, Edvins \\ Miklasevics**/*** \\ *Children`s Clinical University Hospital, Riga, Latvia \\ ** Pauls Stradins Clinical University Hospital, Riga, Latvia \\ ***Riga Stradins University, Department of Paediatrics, Latvia
}

\begin{abstract}
Summary
The first case in Latvia of Panton - Valentine leukocidin (PVL) positive methicillin susceptible Staphylococcus aureus (MSSA) pneumonia in an adolescent with novel influenza A H1N1 is described.

A 15 year old boy was admitted to intensive care suffering from severe respiratory failure with bilateral necrotic pneumonia. The presence of influenza A H1N1 was confirmed by PCR. Invasive S. aureus was spa type t435 and Panton-Valentine leukocidin gene positive. He received therapy with ceftriaxone, oxacillin, clindamycin and oseltamivir phosphate and underwent two chest operations. He was discharged after 58 days in hospital.
\end{abstract}

Key words: H1N1, S. aureus, PVL; MSSA

\section{AIM OF THE DEMONSTRATION}

Novel influenza type A $(\mathrm{HlNl})$, or pandemic flu was first identified in April 2009 in Mexico and rapidly worldwide. On 11 June, 2009 the World Health Organization formally confirmed H1NI influenza pandemic. The course of illness was mild or moderate in most cases and hospitalization due to severe influenza was required mainly for persons from the following risk groups: children under 2, pregnant women those with underlying chronic disease and the immunocompromised (14).

In Latvia the novel pandemic influenza $\mathrm{A} / \mathrm{HlNl}$ virus was first identified in June 2009; and new cases appeared sporadically until November when more than 50 new cases of pandemic flu were identified per week (15). During the period 20 - 26 November, 2009, very high activity was reported in Europe including Latvia, with children up to 15 years of age affected to unusually high degrees (16)

Uncomplicated human influenza virus infection causes transient tracheo - bronchitis due as the virus attaches to tracheal and bronchial epithelial cells. The main complication is extension of viral infection to the alveoli often complicated with bacterial infection resulting in severe pneumonia. Necrotizing $S$. aureus pneumonia has long been recognized, but the association with PVL was made less than ten years ago. PVL positive $S$. aureus necrotising pneumonia is often lethal and can follow respiratory infections, especially influenza. Numerous cases since have been reported worldwide. Panton Valentine Leukocidin is a bicomponent pore-forming $S$. aureus exotoxin which mainly acts on neutrophils. PVL producing $S$. aureus may be either methicilin sensitive or resistant, however mainly associated with community acquired methicilin resistant $S$. aureus.

Here, we report the first case in Latvia of methicillin susceptible Panton - Valentine leukocidin (PVL) positive $S$. aureus severe pneumonia in an adolescent with influenza A HiNı.

\section{CASE REPORT}

A 15 - year old boy was admitted to Daugavpils Regional Hospital on the evening 29 November 2009 with a 4 day history of low-grade to high fever, vomiting and a dry cough with haemoptysis and discomfort behind the sternum on the day of the hospitalization.

A chest X-ray, performed on admission, showed total right sided pneumonia, the patients' CRP (C- reactive protein) was $253,65 \mathrm{mg} / \mathrm{l}$ (N 0-7,9 $\mathrm{mg} / \mathrm{l})$ with other indicators as follows: $\mathrm{HGB} 15,8 \mathrm{~g} / \mathrm{dl}, \mathrm{RBC}-5,56 \times 10^{6}(\mathrm{~N}$ $4,5-5,3)$, WBC $-7,5 \times 10^{3}(\mathrm{~N} 4,5-13)$, PLT $160 \times 10^{3}(\mathrm{~N}$ 181-521). A nasopharyngeal swab was taken to detect respiratory viruses. Empiric antibacterial therapy with ceftriaxone and metronidazole was commenced. After a few hours the patient was moved to the intensive care unit and subsequently to the main children's hospital due to his progressive respiratory insufficiency. On the morning of November 30 the patient was transferred to the Childrens Clinical University Hospital (CCUH) in Riga. On arrival at CCUH, Riga, the patient had difficulty breathing and had signs of severe respiratory failure; he was sitting in an enforced position, had tachypnea (3540 times per min.) with loud, groaning breathing and intercostal retractions and his blood pressure was raised $(200 / 87 \mathrm{mmHg})$. Auscultation of the lungs showed unilateral dullness on the right side. 
The chest X-ray showed multiple focal shadows on both sides of the lungs and unilateral intensive infiltration in the middle part of the right lung that suggested severe bilateral pneumonia (Pict. 1). Laboratory findings showed significant changes in blood gases - decreased $\mathrm{pO}_{2}-70,6$ $\mathrm{mmHg}$ ( $\mathrm{N} 71-104 \mathrm{mmHg}$ ), increased $\mathrm{pCO}_{2}-78,6 \mathrm{mmHg}$ (N 32-46 mmHg), base excess was $6 \mathrm{mmol} / \mathrm{l}$ ( $\mathrm{N}-5-$ $5), \mathrm{pH}-7,28$ (N 7,37-7,45) and still elevated CRP $261,65 \mathrm{mg} / \mathrm{l}$, urea and creatinine levels were normal. His blood count at admission was normal except of "left shift" with $1 \%$ of metamyelocytes.

His history was unremarkable except miozitis after acute respiratory infection in January, 2008 and recurrent faringitis in the summer 2008.

He was admitted to the intensive care unit and empiric oral antiviral therapy with oseltamivir phosphate (75mg twice daily) and intravenous antibacterial therapy with ceftriaxone and oxacillin in additional to antihypertensives and symptomatic therapy were commenced. One day later clindamycin was added.

Novel influenza A HINl infection was confirmed by PCR and S. aureus isolated from blood and pleural fluid on the day of admission were methicillin susceptible, Panton Valentine leukocidin producing and were spa type $t 435$. Antibacterial susceptibility was determined according to CLSI standards (M2-A9, M100-S16). The lukSF-PV genes were detected by PCR (4). Chromatograms of the spa sequences were analysed by Ridom StaphType software (Ridom $\mathrm{GmbH}$ ).

Blood analyses that were taken two days later showed elevated inflammatory markers interleukin 6 (Il6) was $172 \mathrm{pg} / \mathrm{ml}(\mathrm{N}<10 \mathrm{pg} / \mathrm{ml})$ and calcitonin prohormone procalcitonin (PCT) level $2-10 \mathrm{ng} / \mathrm{ml}(\mathrm{N}<0,5 \mathrm{ng} / \mathrm{ml})$.

Eleven hours after admission due to increasing respiratory insufficiency mechanical pulmonal ventilation was started and continued for 15 days. The general condition of the patient remained severe for more than five days.

On the $16^{\text {th }}$ day the boy underwent operative therapy with a right side thoracotomy and resection of S4, S5 of the right lung (Pict.2) because of the severe condition due to pneumothorax and empyema. Further investigations of postoperative material revealed necrosis and inflamation of lung tissues. After the operation his general condition improved and it was decided to continue conservative therapy with antibiotics, but due to a post operative fistula of the right lung, the surgery was repeated after 3 weeks and the fistula was closed. The patient underwent repetitive bronhoscopies and antibacterial therapy with ceftriaxone (14 days), oxacillin (14 days), clindamycin (21 days) and oseltamivir phosphate ( 5 days). With this treatment blood cultures became negative on the $14^{\text {th }}$ day of hospitalization. His general condition improved and after 58 days in hospital the patient was discharged.

\section{DISCUSSION}

Bacterial infection with Staphylococcus aureus is a known cause of severe illness often occurring after, and complicating, viral respiratory infection $(9,17)$. In vitro $S$. aureus will adhere mainly to poorly differentiated airway epithelial cells, confirming its tropism for injured and remodelled airway epithelium (7).

Panton - Valentine leukotoxin (PVL) is a pore forming staphylococcal $\gamma$ toxin encoded by the lukSF-PV genes (10), and is associated with skin abscesses and necrotizing pneumonia (6). Pneumonia often arises from the blood born spread of organisms from infected tissues and can follow viral respiratory infections, especially influenza (8). From 2002-3 isolates it has been estimated that $<2 \%$ of $S$. aureus in the UK were PVL positive, most were methicillin sensitive, with $65 \%$ of them associated with skin and soft tissue infections, 17\% with pneumonia (3). Gillet et al (1) compared the clinical features of PVL positive and PVL negative pneumonias and found in contrast to PVL-negative pneuomonia patients, those with PVL-S. aureus were younger and mostly immunocompetent. They presented with influenza like symptoms, high fever, tachycardia, tachypnoe, heamoptysis and bilateral infiltrates, and pleural effusion more often. Other case series confirm the characteristics and severity of PVL - positive infections. $(7,4,5,11)$. The symptoms of the described patient were equal with the described features.

Combined empirical antibacterial therapy of wide spectrum antibiotics is used in life-threating infections. We used ceftriaxone and oxacillin empirically to treat atypical pneumonia in addition to antiviral therapy with oselatamivir phosphate (12). Oseltamivir phosphate was started due to possibility of influenza infection and severe condition of patient (18). Due to a rapidly worsening general condition and changes in the chest X-ray which was similar to PVL caused pneumonia, clindamycin was added one day after the initial therapy. International guidelines not been published for the therapy of necrotising pneumonia caused by PVL positive $S$. aureus, however some local guidelines do exist (19), and mostly recommend the use of protein synthesis inhibiting antibiotics including clindamycin - when guided by in vitro susceptibility results. In addition, several publications recommend the addition of clindamycin in the treatment of toxin producing $\mathrm{Gr}+$ bacteria as it may reduce toxin production (13).

Besides conservative therapy, surgery was also used due to the patients severe condition after two weeks, treatment with broad spectrum antibiotics and intensive care therapy. There is controversy over the indications and best timings for surgery in cases of pulmonary necrosis, especially in children. In our case the operation was done successfully despite the postoperative fistula, after the lobectomy, which prolonged the patients stay in hospital.

PVL positive $S$. aureus with spa type 1435 are mostly methicillin susceptible and are spread in Latvia with sporadic cases in Poland, Austria, Romania and Hungary (2). In Latvia PVL positive $S$. aureus with spa type 4435 is spread among children with purulent skin and soft tissues infections (Cupane, in preparation).

Our described case exposes that PVL - positive $S$. aureus with spa type $t 435$ can complicate influenza in otherwise healthy children, with rapid progression to 
severe pneumonia that needs complicated and long management of the illness.

\section{Conflict of interest: None}

\section{REFERENCES}

1. Gillet $Y$, Issartel B, Vanhems $P$, Fournet JC, Lina G Bes M, et al. Association between Staphylococcus aureus strains carrying gene for Panton - Valentine leukkocidin and highly lethal necrotaising pneumonia in young immunocompetent patients // Lancet, 2002; 359: $753-759$

2. Grundmann H, Aanensen DM, van den Wijngaard CC, Webster C, Tami A, Feil EJ, et al. // PLoS Med, $2010 ; 12: 7(1)$

3. Holmes A, Ganner S, McGuane S, Pitt TL, Cookson BD, Kearns AM. Staphylococcus aureus isolates carrying Panton - Valentine leucocidin gene in England and Wales: frequency, characterization, and association with clinical disease // J Clin Microbiol, 2005; 5: 2384. - 2390

4. Hussain A, Robinson G, Malkin J, Duthie M, Kearns A, Perera N. Purpura fulminans in a child secondary to Panton - Valentine leukocidin producing Staphylococcus aureus // J Med Microbiol, 2007; 56: 1407- 1409

5. Kravitz GR, Dries DJ, Peterson ML, Schlievert PM. Purpura fulminans due to Staphylococcus aureus // Clin Infec Dis, 2005; 40: 941-947

6. Lina G, Piemont Y, Godail-Gamot F, Bes M, Peter MO, Gauduchon V, et al. Involvment of PantonValentine leukocidin-producing Staphylococcus aureus in primary skin infections and pneumonia // Clin Infec Dis, 1999; 29:1128-1132

7. Mongodin E, Bajorel O, Hinnarsky J, Puchelle E, de Bentzmann S. Cell wall-associated protein A as a tool for immunocolonization of Staphylococcus aureus in infected airway epitelium // J Histochem Cytochem, 2000; 48: 523 - 534

8. Morgan M. Staphylococcus aureus, Panton Valentine leukocidin, and necrotising pneumonia // BMJ, 2005; 331: 793 - 794

9. Peltola VT, McCullers JA. Respiratory viruses predisposing to bacterial infections: role of neuraminidase // Pediatr Infect Dis J, 2004; 23: 87- 97

10. Prevost G, Mourey L, Colin DA, Menestrina G. Staphylococcal pore - forming toxins // Microbiol Immunol, 2001; 257: $58-83$

11. Roberts JC, Gulino SP, Peak KK, Luna VA, Sanderson R. Fatal necrotizing pneumonia due to a Panton - Valentine leukocidin positive communityassociated methicillin - sensitive Staphylococcus aureus and Influenza co- infection: a case report // Ann of Clin Microbiol Antimocrob, 2008; 7: 5
12. Sectish TC, Prober CG. Chapter 397 - Pneumonia // In Kliegman RM, Behrman RE, Jenson HB,Stanton BF. Nelson Textbook of Pediatrics. 18th ed. Philadelphia: Saunders Elsevier; 2007; 1795 - 1799

13. Stevens DL, Ma Y, Salmi DB, McIndoo E, Wallance RJ, Bryant AE. Impact of Antibiotics on Expresion of Virulence-Associated Exotoxin Genes in Methicillin-Sensitive and Methicillin-Resistant Staphylococcus aureus //J Infec Dis, 2007; 195: 202- 211

14. Who is more at risk of severe illness? What about other risks? [ WHO web site] 24 February 2010. Available at: http://www.who.int/csr/disease/ swineflu/frequently_asked_questions/risk/en/ index.html Accesesed April 10, 2010

15. Results of laboratory confirmed cases of novel influenza A HiNl. [Infectology Center of Latvia web site] Available at: http://www.lic.gov.lv/ docs/268/2010/jauna\%20gripa_LIC_16012010.pdf Accessed April 16, 2010

16. High pandemic (HINl) 2009 activity, particularly in children. WHO/Europe outbreak update, 30 November 2009. Available at: http://www.euro. who.int/influenza/AH1N1/20091202_1. Accessed April 16, 2010

17. Surveillance for Pediatric Deaths Associated with 2009 Pandemic Influenza A (H1N l) Virus Infection United States, April-August 2009, September 4, 2009 / Vol. 58 / No. 34 / Pg. 941 - 968 Morbidity and mortality weekly report, CDC

18. WHO Guidelines for Pharmacological Management of Pandemic (HlNl) 2009 Influenza and other Influenza Viruses [WHO web site]. February 2010. Available at: http://www.who.int/csr/ resources/publications/swineflu/hlnl_use_ antivirals_20090820/en/index.html Accesed April 16,2010

19. Health Protection Agency. Revised guidance on the diagnosis and management of PVLassociated Staphylococcus aureus infections (PVL-SA) in the UK. [HPA web site] 2008 Available at: http://www.hpa.org.uk/PVL-SA_ FinalGuidance.pdf

\section{Address:}

Liene Cupane,

Riga Stradins University, Department of Paediatrics

Vienibas gatve 45

LV-1004 Riga, Latvia

E-mail: lcupane@tvnet.lv 


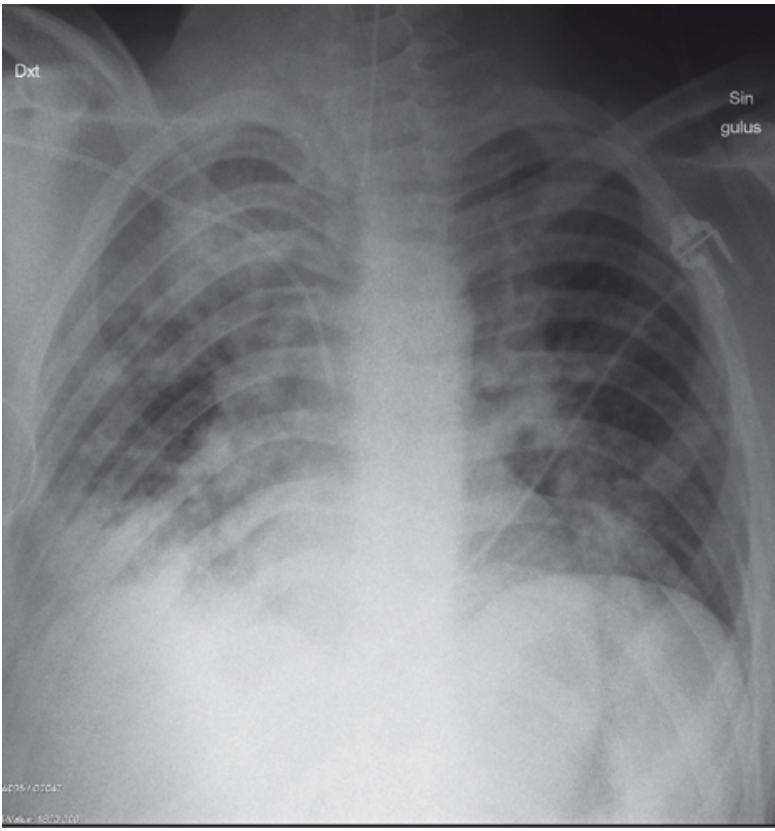

Fig. 1. Chest $X$-ray on admission with multiple focal shadows on the both sides of the lungs and unilateral intensive infiltration in the middle part of the right lung that suggested the severe bilateral pneumonia

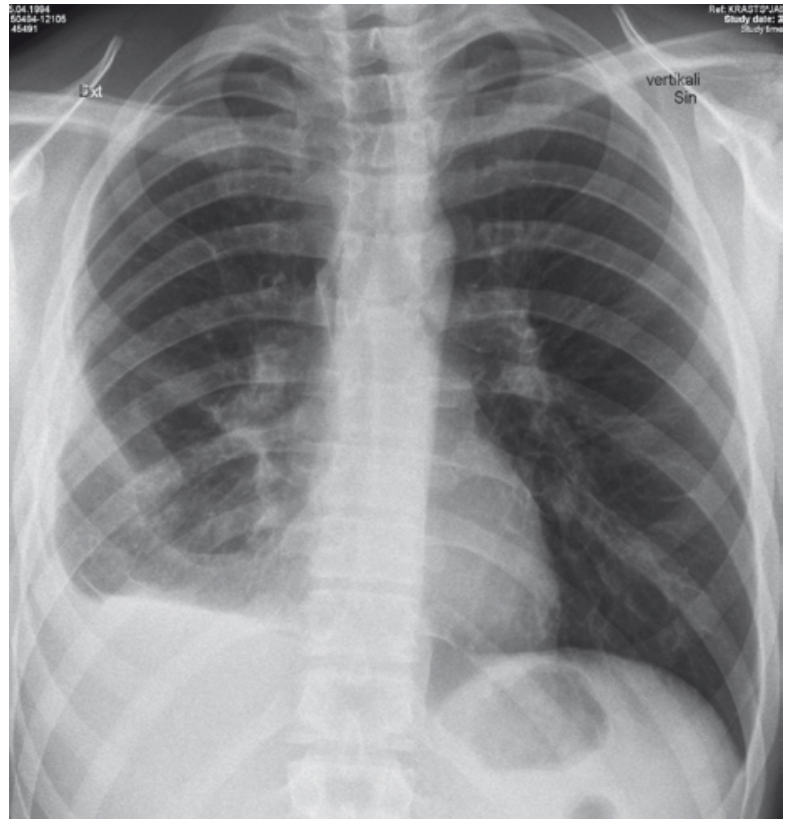

Fig. 2. Chest $X$-ray when the patient was discharged after resection of middle part of the right lung with clinical improvement 